\title{
PENERAPAN ALGORITMA TABU SEARCH DALAM PROSES PENJADWALAN PADA APLIKASI PENJADWALAN KURSUS MOBIL BERBASIS ANDROID
}

\author{
Tri Sutrisno ${ }^{1)}$ \\ 1), trisutrisno90@ gmail.com
}

\begin{abstract}
Abstrak
Tingginya minat dan kebutuhan masyarakat terhadap kepemilikan mobil telah menjadikan peluang usaha dibidang jasa bagi Lembaga Penyedia Teknik (LPT) Eka Jaya Berrindo yang berada di Cirebon. Terdapat fasilitas simulasi menyetir mobil sebagai media pembelajaran awal menjadikan LPT ini lebih diminati, namun dalam proses penjadwalannya masih dilakukan secara manual dan penyediaan informasi jadwal masih menggunakan media white board. Cara ini kurang efektif karena pembuatan jadwal seperti ini memiliki kekurangan seperti sering terjadinya kesalahan (Human Error) dalam penulisan nama siswa dan tanggal jadwal sehingga mengakibatkan kesalah pahaman antara siswa dan front office yang bertugas mengatur jadwal.

Maka dari itu di bangun nya sebuah aplikasi penjadwalan kursus mengemudi mobil menggunakan algoritma yang berhubungan dengan penjadwalan yaitu algoritma tabu search, algoritma tabu search digunakan karena algoritma ini dapat menyelesaikan permasalahan yang ada yaitu penentuan dan pelayanan informasi jadwal kursus, diharapkan penentuan jadwal dan pelayanan informasi jadwal dapat lebih mudah di ketahui dan dikelola serta lebih userfriendly terhadap siswa kursus mengemudi mobil.
\end{abstract}

Kata kunci $\quad$ : Penjadwalan, Kendaraan Mobil, Eka Jaya Berrindo, Algoritma Tabu Sarch

\begin{abstract}
The high interest and needs of the community towards car ownership has made the business opportunity in the field of services for Technical Provider Institution (LPT) Ek a Jaya Berrindo located in Cirebon. There are simulation facilities to drive the car as an early learning media to make LPT is more desirable, but in the process of scheduling is still done manually and provision of schedule information still using white board media. This method is less effective because the making of such a schedule has deficiencies such as frequent occurrence of errors (Human Error) in writing student names and schedule dates resulting in misunderstandings between students and the front office in charge of arranging the schedule.

Therefore in its build an app scheduling course driving the car using algorithms related to scheduling the taboo search algorithm, taboo search algorithm is used because this algorithm can solve existing problems that is determination and service information schedule of the course, expected schedule and service schedule information Can be more easily knowable and manageable as well as more userfriendly towards car driving course students.
\end{abstract}

Keywords: Scheduling, Vehicle Car, Eka Jaya Berrindo, Taboo Search Algorithm

\section{PENDAHULUAN}

Lembaga Penyedia Teknik (LPT) Eka Jaya Berrindo Cirebon merupakan salah satu lembaga penyedia kursus mengemudi kendaraan mobil yang ada di Cirebon. Pada LPT Eka Jaya Berrindo Cirebon. LPT ini merupakan salah satu tempat penyedia kursus mengemudi yang terbilang sedikit lebih maju dari tempat-tempat kursus lainnya. Disini peserta didik kursus disediakan fasilitas simulasi mengemudi terlebih dahulu sebelum langsung belajar mengemudi di jalan. Cara ini terbukti dapat menarik minat calon siswa yang akan melakukan kursus mengemudi mobil.

Kegiatan pertama yang mengawali berjalannya kegiatan pembelajaran kursus mengemudi di LPT Eka Jaya Berrindo ini adalah penjadwalan, penjadwalan atau pembuatan jadwal di LPT ini masih dilakukan secara manual, sarana 
informasi jadwalnya pun masih menggunakan media white board dan dirasa masih belum efektif. Faktanya penggunaan dan pembuatan jadwal dengan menggunakan media white board ini memiliki kekurangan seperti sering terjadi kesalahan (Human Error) dalam penulisan nama siswa, jam atau hari pada jadwal kursus mengemudi mobil, dan juga peserta didik harus datang ke tempat kursus untuk mengetahui jadwal kursus mengemudinya. Salah satu metode yang dapat di pakai untuk penjadwalan yaitu Algoritma Tabu Search dikarenakan Algoritma Tabu Search berfungsi untuk melakukan pencarian waktu dari suatu permasalahan kombinatorial pada penjadwalan kursus mengemudi mobil, dengan menggunakan sistem yang terkomputerisasi diharapkan penjadwalan kursus mengemudi mobil dapat lebih mudah di kelola serta memberikan kenyamanan dan kemudahan bagi peserta kursus mengemudi.

Proses pembuatan jadwal kursus mengemudi memerlukan variable seperti siswa, hari, tanggal dan jam. Selain itu proses ini juga memerlukan ketersediaan dan waktu pengerjaan yang tidak singkat, sehingga seringkali terjadi kesalahan jadwal yang menyebabkkan ketidaknyamanan bagi siswa kursus mengemudi. Proses penjadwalan harus memperhitungkan banyaknya siswa, waktu operasional LPT, dan rentang waktu yang digunakan. Inti dari penjadwalan kursus mengemudi mobil adalah menjadwalkan beberapa variable yang terdiri dari siswa, hari, tanggal dan jam dengan memperhatikan sejumlah batasan dan syarat tertentu.

Berdasarkan latar belakang masalah diatas, maka peneliti dapat merumuskan masalah sebagai berikut:

1. Bagaimana membangun aplikasi penjadwalan yang dapat memberikan kenyamanan bagi siswa dalam menentukan jadwal dan melihat informasi jadwal serta memudahkan bagi pihak LPT dalam mengelola jadwal kursus?

2. Bagaimana mengimplementasikan Algoritma Tabu Search untuk mengoptimalkan waktu jadwal kursus mengemudi mobil dengan menggunakan bahasa pemrograman java android untuk client, bahasa pemrograman web PHP untuk server dan database Mysql ?
Batasan masalah dari penelitian ini adalah sebagai berikut:

1. Penelitian yang dilakukan di Eka Jaya Berrindo Cirebon dibagian Front Office meliputi proses pendaftaran dan pembookingan jadwal kursus mobil bagi siswa.

2. Siswa dapat mencari serta dapat melakukan booking jadwal kursus mengemudi mobil dengan mengimplementasikan algoritma tabu search dalam pencarian jadwal kursus yang akan di booking dengan aturan variable yaitu siswa, hari, tanggal, dan jam.

3. Pada pembuatan nama siswa untuk nama yang tertera di jadwal tidak boleh sama karena dapat menimbulkan kebingungan jika ada nama siswa yang tertera sama dengan siswa lain.

4. Aplikasi penjadwalan kursus mobil ini di bangun menggunakan bahasa pemrograman java berbasis android untuk client, bahasa pemrograman web PHP untuk server dan database Mysql.

Adapun tujuan penelitian yang ingin dicapai adalah untuk merancang dan membangun sebuah aplikasi yang dapat mendukung dan memfasilitasi siswa kursus mengemudi mobil dalam melihat informasi jadwal dan memilih jadwal kursus mengemudi mobil di LPT Eka Jaya Berrindo Cirebon.

Manfaat dari penelitian ini, yaitu:

1. Mempermudah siswa kursus mengemudi mobil dalam melihat informasi dan memilih jadwal kursus mengemudi mobil.

2. Sebagai tambahan fasilitas didalam menghadapi perkembangan zaman dan persaingan perusahaan.

3. Pembuatan jadwal menjadi mudah karena sudah terkomputerisasi dan menggunakan penerapan Algoritma Tabu Search agar pembuatan jadwal kursus mengemudi mudah di kelola.

\section{METODE PENELITIAN}

Metode pengumpulan data yang dilakukan yaitu dengan cara :

1. Observasi

Teknik pengumpulan data dengan melakukan pengawasan terhadap kegiatan yang dilakukan di Eka Jaya Berrindo yang berhubungan dengan pembuatan Aplikasi Penjadwalan Kursus Mengemudi Mobil. 


\section{Wawancara}

Teknik pengumpulan data dengan melakukan Tanya jawab dengan pihak bersangkutan di Eka Jaya Berrindo yaitu Pemilik (Owner) dan Pegawai Eka Jaya Berrindo yang berhubungan dengan pembuatan Aplikasi Penjadwalan Kursus Mengemudi Mobil.

3. Studi Pustaka

Teknik pengumpulan data dengan melakukan pengumpulan literature, jurnal dan referensireferensi yang membahas tentang Aplikasi Penjadwalan Kursus Mengemudi Mobil.

Metode pengembangan perangkat lunak yang akan digunakan adalah RUP (Rational Unified Process) yaitu pendekatan pengembangan perangkat lunak yang dilakukan berulang-ulang (iterative), fokus pada arsitektur (architecturecentric), lebih diarahkan berdasarkan penggunaan kasus (use case driven). RUP merupakan proses rekayasa perangkat lunak dengan pendefinisian yang baik dan penstrukturan yang baik. RUP menyediakan pendefinisian struktur yang baik untuk alur hidup rekayasa perangkat lunak.

Tabu search merupakan prosedur metaheuristik tingkat tinggi untuk menghasilkan solusi yang mendekati optimasi kombinatorial. Kemampuan tabu search dalam menghasilkan solusi mendekati optimal telah dimanfaatkan dalam beragam permasalahan klasik dan praktis dari berbagai bidang mulai bidang penjadwalan hingga bidang telekomunikasi.

Untuk langkah-langkah Algoritma tabu search secara garis besar dapat ditulis sebagai berikut :

1. Inisialisasi variable yang digunakan pada proses tabu search

2. Memberikan statement situasi awal dalam proses pencarian

3. Menampilkan data yang dibuat berupa tabu list jika data yang di cari tidak tersedia

4. Sebuah situasi untuk mencari solusi dari data yang berdekatan atau bertetangga dari statement awal

5. Sebuah situasi untuk mengerjakan fungsi jika solusi dari data yang berdekatan di ambil.

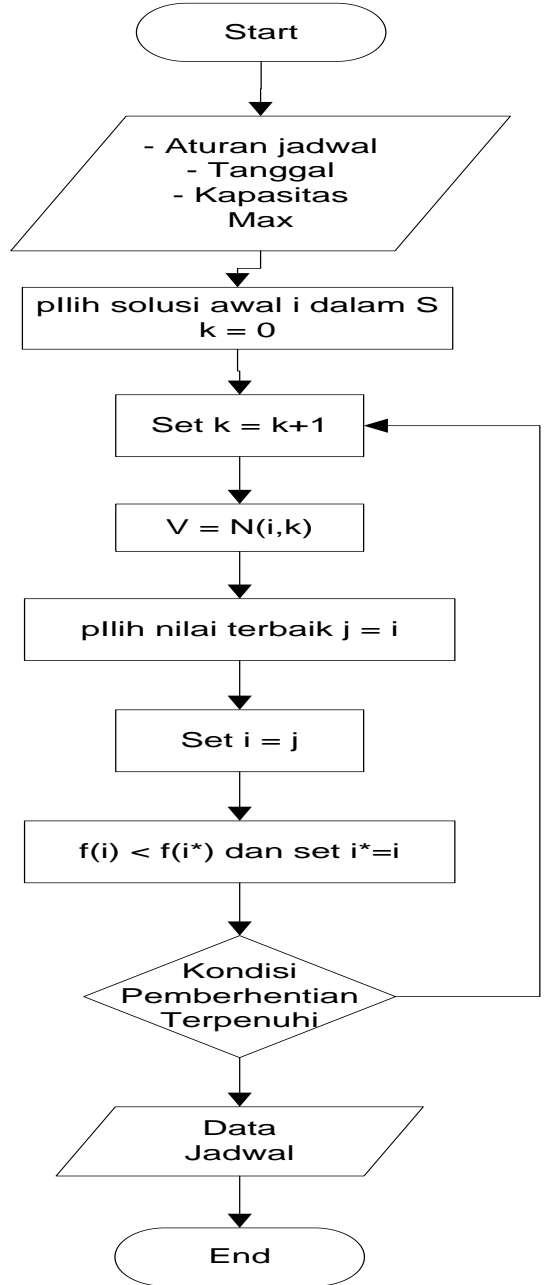

Gambar 1. Flowchart Algoritma tabu search

Pada gambar 1 merupakan gambaran aliran dari flowchart algoritma tabu search. Use Case Diagram proses penjadwalan kursus mobil dengan menggunakan algoritma tabu search, dapat dilihat pada gambar 2.

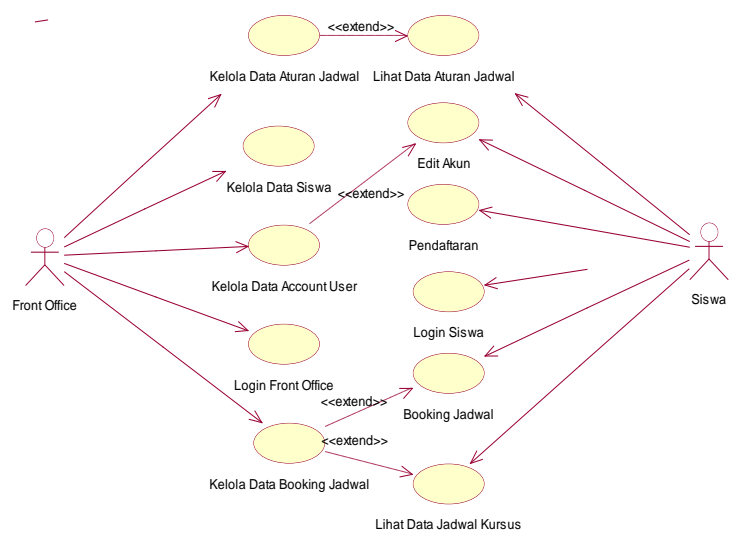

Gambar 2. Use Case Diagram Aplikasi

Gambar 2. Use Case Diagram Aplikasi 


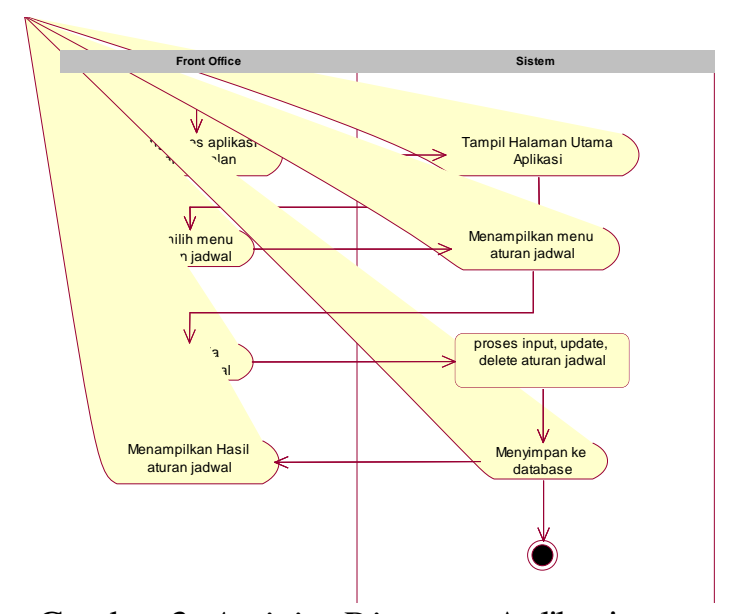

Gambar 3. Activity Diagram Aplikasi

Activity diagram kelola data aturan jadwal merupakan aktivitas dari aktor front office dalam mengelola data aturan jadwal dari LPT Eka Jaya Berrindo. Adapun fasilitas pengeloaan data aturan jadwal yang dapat di lakukan front office yaitu input, update dan delete.

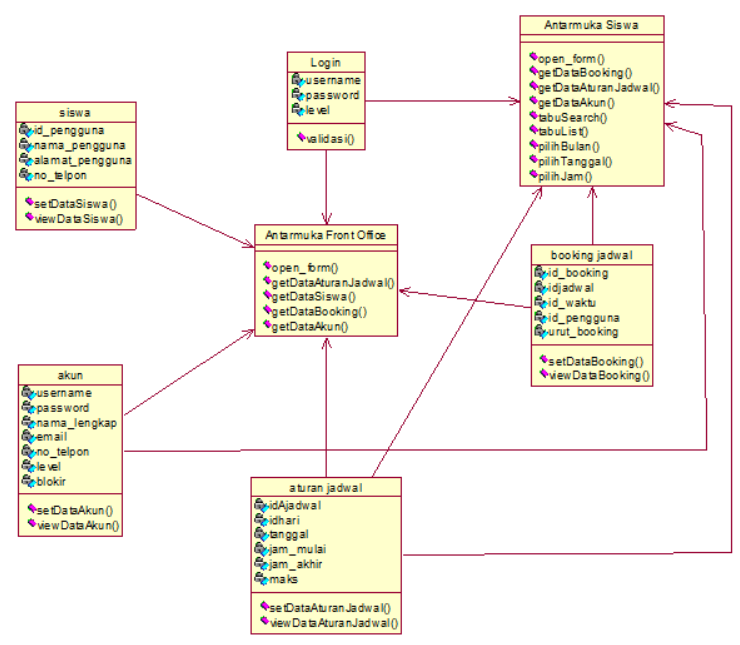

Gambar 4. Class Diagram Aplikasi

Class Diagram merupakan spesifikasi yang jika diinstansikan akan menghasilkan sebuah objek dan merupakan inti dari pengembangan dan desain berorientasi objek.

Untuk class diagram penjadwalan dengan menggunakan metode tabu search diLPT Eka Jaya Berrindo dapat dilihat pada gambar 4. Sequence diagram login front office merupakan skenario dari aktor front office dalam melakukan login terhadap sistem untuk dapat mengelola data pada aplikasi penjadwalan. Untuk skenario sequence diagram login front office dapat dilihat pada gambar 5.

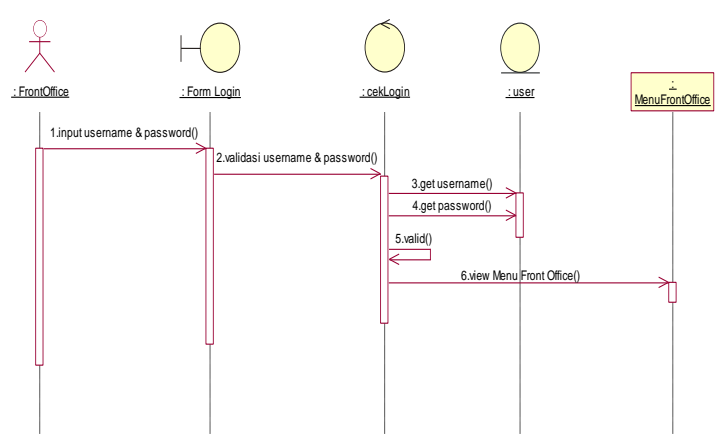

Gambar 5. Sequence Diagram Aplikasi

\section{HASIL DAN PEMBAHASAN}

Implementasi perancangan pada sistem aplikasi penjadwalan kursus mobil dibangun dengan menggunkan bahasa pemrograman web PHP pada server dan java android pada client, program untuk server dijalankan pada web browser dan program untuk client dijalankan pada sistem operasi android, hasil dari implementasi program pada sisi server yaitu pengelolaan data berupa data siswa, data aturan jadwal, data booking jadwal, dan data account user, sedangkan hasil implementasi program pada sisi client yaitu melihat jadwal dan booking jadwal dengan menggunkan algoritma tabu search.

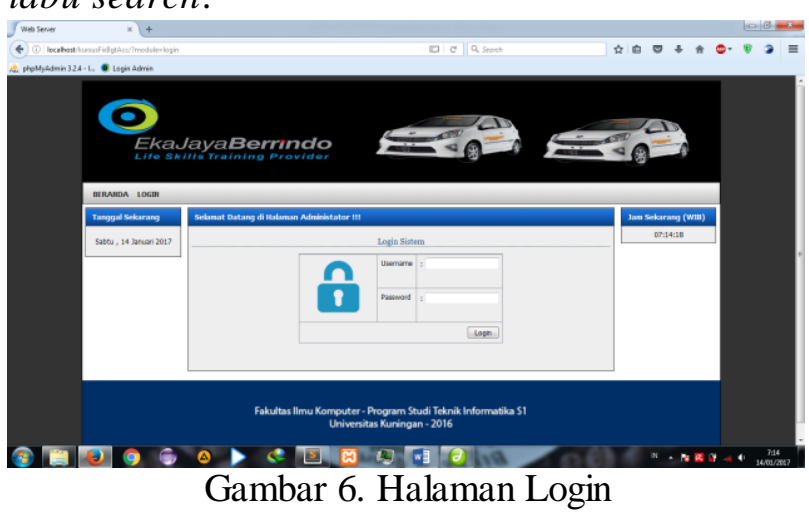

Pada Gambar 6 halaman login front office ini menampilkan form untuk menuju halaman admin yang mengelola data, berikut adalah tampilannya. Pada Gambar 7 merupakan gambar halaman utama front office ini menampilkan menu yang dapat di pilih untuk mengelola data aplikasi penjadwalan, berikut adalah tampilannya 


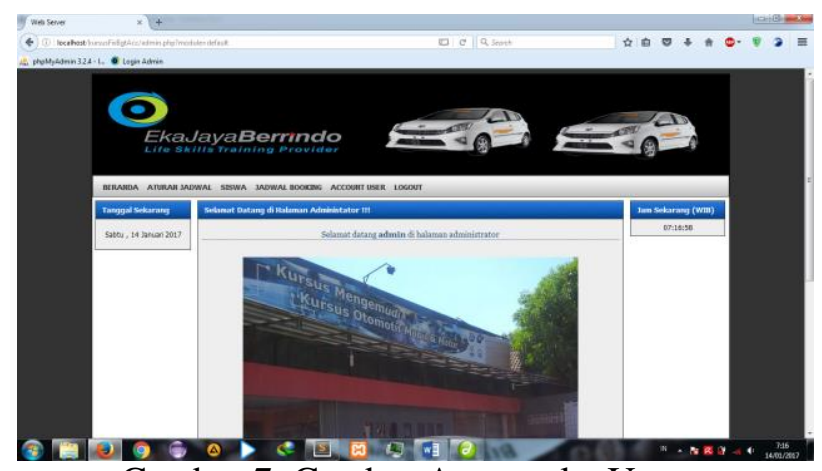

Gambar 7. Gambar Antarmuka Utama

Pada Gambar 8 merupakan gambar halaman Aturan Jadwal ini menampilkan tabel yang berisi aturan jadwal yang telah di inputkan dan juga terdapat tombol tambah untuk menambah aturan jadwal, berikut adalah tampilanya.

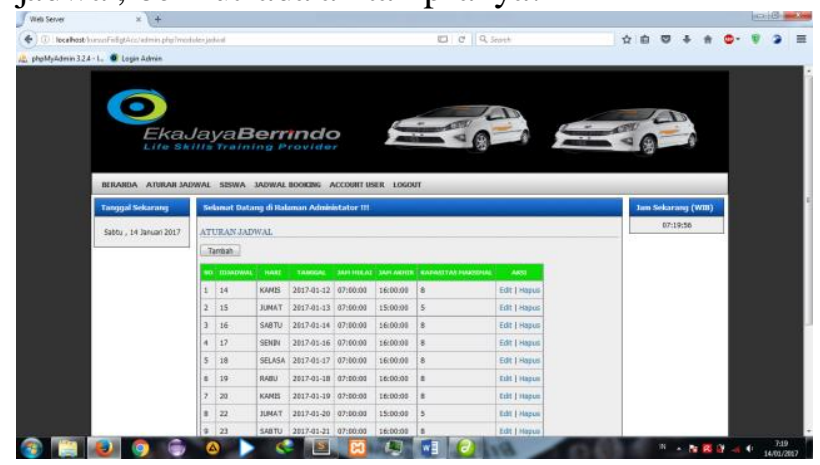

Gambar 8. Gambar Halaman Aturan Jadwal

Pada Gambar 9 merupakan gambar halaman siswa ini menampilkan tabel yang berisi daftar siswa yang telah di inputkan dan juga terdapat tombol tambah untuk menambah data siswa, berikut adalah tampilanya.

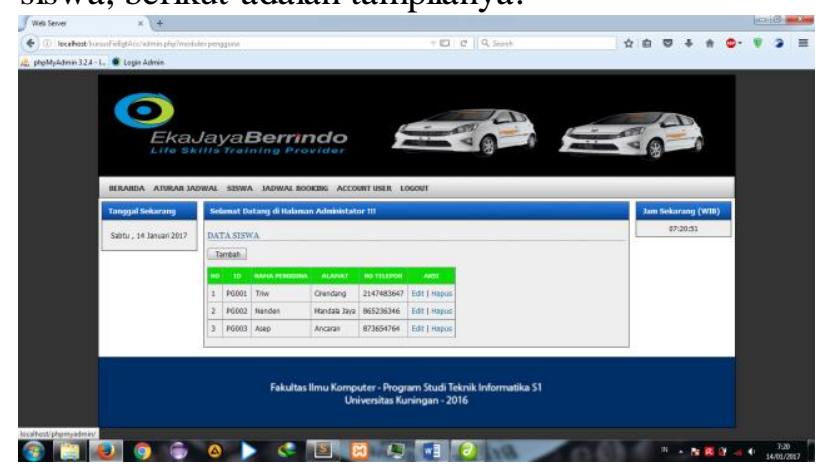

Gambar 9. Gambar Halaman Siswa

Pengujian black box merukapan pengujian yang berfokus pada spesifikasi fungsional dari perangkat lunak, penguji atau tester akan mendefinisikan dan melakukan pengetesan terhadap spesifikasi fungsional program
Tabel 1. Pengujian Halaman Login Front Office (Web Server)

\begin{tabular}{|c|c|c|c|}
\hline \multicolumn{4}{|c|}{ Kasus dan Hasil Uji (Benar) } \\
\hline Item Uji & $\begin{array}{l}\text { Yang } \\
\text { diharapkan }\end{array}$ & Pengamatan & Kesimpulan \\
\hline \multirow[t]{2}{*}{ Halaman Login } & $\begin{array}{l}\text { Halaman } \\
\text { login akan } \\
\text { menampilkan } \\
\text { halaman form } \\
\text { login bagi } \\
\text { front office } \\
\text { untuk sisi } \\
\text { server dan } \\
\text { siswa untuk } \\
\text { sisi client, } \\
\text { jikatidak ada } \\
\text { id dalam } \\
\text { database } \\
\text {,sistem akan } \\
\text { memunculkan } \\
\text { alert. } \\
\end{array}$ & $\begin{array}{l}\text { Halaman } \\
\text { form login di } \\
\text { tampilkan } \\
\text { saat aplikasi } \\
\text { pertama kali } \\
\text { di jalankan } \\
\text { baik dari web } \\
\text { server untuk } \\
\text { front office } \\
\text { maupun dari } \\
\text { android untuk } \\
\text { siswa setelah } \\
\text { melakukan } \\
\text { login muncul } \\
\text { alert } \\
\text { javascript. }\end{array}$ & Valid \\
\hline & $\begin{array}{l}\text { Tidak muncul } \\
\text { alert dan } \\
\text { langsung } \\
\text { direct ke } \\
\text { halaman } \\
\text { utama } \\
\text { masing- } \\
\text { masing jika } \\
\text { terdapat id di } \\
\text { database }\end{array}$ & $\begin{array}{l}\text { aplikasi di } \\
\text { jalankan } \\
\text { kembali dan } \\
\text { hala-man } \\
\text { menginputkan } \\
\text { id masing - } \\
\text { masing, } \\
\text { sistem } \\
\text { memunculkan } \\
\text { menu utama } \\
\text { kelola data } \\
\text { aplikasi bagi } \\
\text { front office } \\
\text { dan booking } \\
\text { jadwal bagi } \\
\text { siswa. }\end{array}$ & Valid \\
\hline
\end{tabular}

\section{KESIMPULAN}

Berdasarkan hasil analisa dan perancangan serta pemanfaatan metode tabu search pada aplikasi penjadwalan kursus mobil di LPT Eka Jaya Berrindo Cirebon, maka diperoleh kesimpulan sebagai berikut:

1. Aplikasi ini dapat melakukan pembuatan jadwal kursus dan siswa dapat memilih waktu untuk jadwal kursus sesuai dengan kebutuhannya dengan catatan waktu tersebut masih tersedia dan belum dipilih oleh siswa lain.

2. Jika waktu yang di inginkan oleh siswa tidak tersedia atau telah dibooking oleh siswa lain maka sistem akan menampilkan solusi berupa tabu list atau tanggal yang tersedia sehingga dapat meningkatkan kenyamanan pada pelayanan dari pihak LPT dalam hal penjadwalan.

3. Dengan adanya fasilitas booking atau 
memilih sendiri jadwal yang siswa inginkan, siswa dapat mengetahui ketersediaan waktu booking sehingga dapat dipilih alternatif waktu lain jika jadwal kursus yang diinginkan tidak tersedia dalam sistem atau sudah dipilih oleh siswa lain.

\section{SARAN}

Setelah penulis mengadakan penelitian, maka ada beberapa saran yang ingin penulis kemukakan agar aplikasi berjalan maksimal, antara lain:Untuk mengoperasikan program aplikasi ini, diperlukan adanya pelatihan khusus terlebih dahulu terhadap front office.

1. Pengisian data aturan jadwal harus dilakukan dengan teliti sehingga hasil yang dikeluarkan sesuai dengan apa yang diharapkan.

2. Sistem ini belum memiliki proses pembatasan dalam pembookingan jadwal, jadi dalam pembatasan pembookingan masih di pantau oleh front office.

3. Sistem ini mengharuskan front office menginputkan slot aturan jadwal per-tanggal, sistem ini belum memiliki proses pembuatan slot aturan jadwal per-bulan.

\section{DAFTAR PUSTAKA}

Aditya, F. dan Handoyo, E. (2011). "Perbandingan Paid Hosting dan Free Hosting Berdasarkan Fasilitas Backup yang ada", Jurnal Teknologi, VOL. 4, NO. 1, JUNI 2011, h. 1-5.

Akhmad, Dharma Kasman. (2015). Aplikasi Pemesanan Tiket Online Berbasis Web \& PHP.

Cirebon : CV. ASFA Solution

Aladag, C. H. and Hocaoglu, G. (2007). A Tabu Search Algorithm to Solve A Course Timetabling Problem. Haccettepe Journal of Mathematics and Statistics Volume 36 (1) (2007), 53-64.

A.S, Rosa. (2011). Modul Pembelajaran Rekayasa Perangkat Lunak. Bandung : Modula

A.S, Rosa dan M. Salahuddin. (2015). Rekayasa Perangkat Lunak Terstruktur dan Berorientasi Objek. Bandung : Informatika Bandung
Budi Sutedjo, Dharma Oetomo dkk. (2006).

Konsep dan Aplikasi Pemrograman

Client

Server dan Sistem Terdistribusi.

Yogyakarta: Penerbit ANDI

Efendi, I.(2014).Pengertian Domain dan Hosting.[Online]. Tersedia :

http://www.it-jurnal.com/2014/11/pengertiandomain-dan-hosting.html [11 Mei 2016]

Ginting, Rosnani. (2009), Penjadwalan Mesin, Penerbit Graha Ilmu, Yogyakarta

Hakim, Lukmanul. (2008). Membongkar Trik Rahasia Para Master PHP.

Yogyakarta : Lokomedia.

Jogiyanto. (2006). Sistem Informasi Manajemen, Andi Offset, Yogyakarta. 